\title{
非構造格子系における界面体積追跡法の検討*
}

\author{
永武拓*1, 功 刀資 彰*2
}

\section{A Study of Interfacial Volume Tracking Method for Unstructured Grid System Based on MARS}

\author{
Taku NAGATAKE*3 and Tomoaki KUNUGI \\ ${ }^{* 3}$ Department of Nuclear Engineering, Kyoto University, \\ Yoshida-honmachi, Sakyo-ku, Kyoto-shi, Kyoto, 606-8501 Japan
}

\begin{abstract}
There are several methods of tracking gas-liquid interface of multi-phase flows (MF). In these methods, the MARS (Multi-interfaces Advection and Reconstruction Solver) developed by one of the authors has been successfully applied to many problems, because of the accurate volume/mass conservation of fluid. But the MARS was developed on a structured gird system, and it is difficult to get the results with high accuracy for the complex geometry of the solution domain. On the other hand, the usage of an unstructured grid system in the computational fluid dynamics is now to be a popular manner for handling the complex geometry of the computational domain. In the present stydy, we have developed an interface-volume tracking algorithm on the unstructured grid system for the MF numerical simulation based on the MARS. This paper describes the interface-volume tracking procedure based on the MARS for the unstructured grid system, and discusses on the accuracy of the reconstruction of the interfaces and also discusses on the conservation of the volume of fluid through the advection process.
\end{abstract}

Key Words: Multi-phase Flow, Numerical Analysis, MARS, Unstructured Grid, Interface Volume Tracking

\section{1. 緒}

気液二相流は気体と液体が混在する流れであり, 沸 騰水型原子炉, ボイラー等伝熱装置, 化学工学機器な ど幅広い分野で利用されている. その数值解析手法と して，例えば原子炉内サブチャンネル解析などでは流 れ場に出現する様々な混相流動場を流動様式に分類し, 各流動梯式に対する基礎的な実験で得られた実験相関 式を「構成方程式」の形で空間平均された混相流運動 方程式に取り込むことで数值解析モデルを構築してい る.しかしながら，このような手法で得られた解析結 果は，用いられる構成方程式の精度に大きく依存する ため,「数值予測」は困難である.これに対して, 気 液界面を追跡する手法は表面張力を考慮できるため, 構成方程式が不要となり, 現象の「数值予測」が可能

* 原稿受付 2007 年 10 月 19 日.

*1 京都大学大学院工学研究科原子核工学専攻(业 606-8501 京 都市左京区吉田本町).

*2 正員, 京都大学大学院工学研究科原子核工学専攻.

E-mail : t-nagatake@nucleng.kyoto-u.ac.jp
となる.

気液界面を追跡あるいは捕獲する混相流数值解析 手法としては, MAC 法(1), VOF(Volume of Fluid)法(2), Level-Set 法(3), CIP 法(4), MARS ${ }^{(5)}$ などが挙げられる. これらの手法のうち MARS は VOF 法と同様, 計算セ ル内の流体の占有率（VOF 率 : $F$ ）を連続の式に基づ いて輸送することにより界面を輸送する手法であり， $F$ のみで界面形状を記述でき, 流体の体積保存性が良 いことが特徴である.VOF 法は連続の式に基づいて F を輸送する際に界面形状を考慮しないため, 例えば, 円形の気泡が四角形になるといつた問題がある.これ に対し, MARS は界面勾配を考慮した輸送を行うため, 界面形状及び質量・体積保存性ともに優れており, 現 在のところ最も精度の高い界面追跡手法である. しか し, 現在の MARS は構造格子系を対象に開発されたた め, 複雑な形状を有する計算領域の解析では境界面を 高精度に表現することが出来ず，このような場の高精 度解析は不可能である. 一方, 境界適合格子系や非構 造格子系は境界面に沿ったメッシュを利用できるため, 
複雑な境界を持つ領域における混相流動解析の高精度 化が期待できる.

本研究では, 非構造格子系を用いた MARS を構築す るための第一段階として, MARS の考え方を基にした 非構造格子における新しい界面輸送法を考案した。 そ して, 2 次元体系における界面輸送解析を行い, 本手 法の解析精度の検証を行った. また, 非構造格子系に おける界面面積輸送時に生ずる輸送面積の保存性につ いて検討した.

\section{2. 主な記号}

\begin{tabular}{|c|c|}
\hline$F$ & : VOF 率 \\
\hline$l$ & : 境界辺長さ $[\mathrm{n}$ \\
\hline n & : 法線へ \\
\hline$t$ & : 任意時刻 $[\mathrm{s}]$ \\
\hline$t_{0}$ & : 初期時刻 $[\mathrm{s}]$ \\
\hline$\delta t$ & : フラクショナ \\
\hline $\mathbf{u}$ & : 流速 $[\mathrm{m} / \mathrm{s}]$ \\
\hline$u_{\text {ham }}$ & : 要素境界速度 \\
\hline$u_{n}$ & : 輸送距離の \\
\hline$V$ & : 要素面積 $\mathrm{m}^{2}$ \\
\hline \multicolumn{2}{|l|}{ 添字 } \\
\hline$\alpha$ & : 要素境界辺 \\
\hline$e$ & :注目要素 \\
\hline theo & : 理論値 \\
\hline cal & : 計算値 \\
\hline$S$ & : 要素境界 \\
\hline
\end{tabular}

\section{3. 計算手法}

まず, MARS の特徵である界面輸送法について簡単 に述べ, 次いで新たに考案した MARS の考え方に基づ く非構造格子系における界面輸送法について述べる.

3・1 MARS MARS はVOF法における弱点で ある界面形状の保存性を克服した界面輸送法である. VOF 法の特徴である質量および体積の完全な保存性 を保ちつつ, その欠点である界面勾配輸送の不正確性 を克服するため, 界面勾配を考慮した流体体積輸送を 実現している.

界面の輸送は, MARS と同様に連続の式を保存系に 書き直した以下の方程式に基づいて行う.

$$
\frac{\partial F}{\partial t}+(\mathbf{u} \cdot \nabla) F=\frac{\partial F}{\partial t}+\nabla \cdot(F \mathbf{u})-F \nabla \cdot \mathbf{u}=0
$$

MARS は要素内で界面を一次関数で近似する.すな わち各要素で界面の勾配を計算する必要がある．この
界面勾配は隣接する $F$ の勾配から求める. 次いで, 各 界面要素においては図 1 に示すように $F$ と Fの勾配よ り界面を再構築する. この界面を基に, 要素境界面で 定義した速度場を用いて VOF 率を隣接要素へ輸送す る. この際, VOF 率自身を輸送するのではなく, 積分 量である境界面を横切る流量 $\Delta F$ を輸送するため, 体 積保存性 (2 次元では面積保存性) に優れたスキーム となっている.

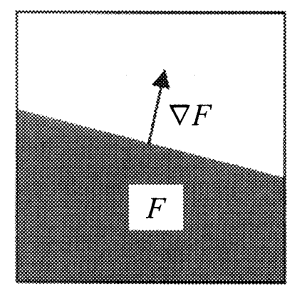

Fig.1 Reconstruction of free surface

\section{3・2 非構造格子系における界面法線ベクトル} 非構造格子系における界面法線ベクトルの計算法を検 討する. まず界面勾配を決める F の勾配は Gauss-Green の定理に基づく次式の周回積分(7)を行うことにより算 出した.

$$
\nabla F=\frac{1}{V} \oint F \mathbf{n} d S=\frac{1}{V} \sum_{\alpha} l_{\alpha} F_{\alpha} \mathbf{n}_{\alpha}
$$

構造格子系 MARS では, 表面張力の計算に CSF モデ ルの使用しているが, 気液界面法線ベクトルの計算法 には 2 通りの方法がある.すなわち, 計算点を格子点 とする ALE 形式とセル境界とする MAC 形式である. 図 2 に示すように, ALE 形式では格子点 (O印) を中 心に, 周囲セルの $F$ の定義点である重心位置を通る積 分経路 (図中の点線)を選んだ. 一方 MAC 形式では, 定義点 (回印) を含む両側の要素周り（図中の破線） を積分経路とした. 界面を再構築する際, 要素中心の 界面法線ベクトルが必要となる。これはそれぞれのス キームで求めた法線ベクトルを補間して求めた.

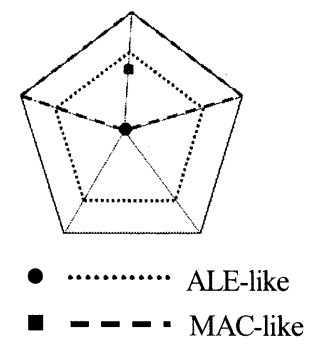

Fig.2 ALE-like and MAC-like scheme 
$3 \cdot 3$ 界面再構築法 まず, 要素中心の界面法線 ベクトルと, 要素を構成する格子点を結ぶ 3 本のベク トルとの内積を計算する. このうち絶対值が最大とな るベクトルを含む辺と気液界面は必ず交差することを 利用し，式(3)を用いて界面を再構築する ${ }^{(8)}$. 式(3)では 気液界面と各辺との交点が, その辺上のどの位置に存 在するかを比で表現している. 図 3 は辺 $\mathrm{BC}$ と気液界 面が交差する場合を示している。ここで $F^{*}$ 汶気液界面 が頂点A を通る場合の VOF 率で, $F^{*}=\mathrm{BD} / \mathrm{BC}$ である. 次いで, 構造格子系 MARS と同様に界面勾配を考慮し, 要素境界の辺上で定義した速度場を用いて輸送流量 $\Delta$ $F$ を求め, それを流速べクトル方向の隣接要素へと輸 送する.
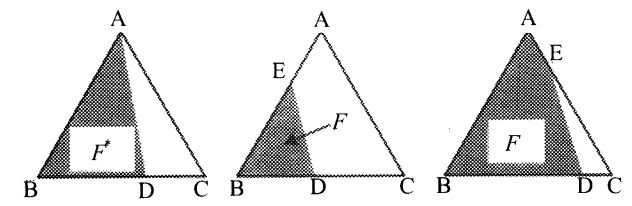

Fig.3 Interface reconstruction on unstructured grid system

$$
\begin{aligned}
f \circ r\left(F \leq F^{*}\right) & \frac{\mathrm{BE}}{\mathrm{AB}}=\sqrt{\frac{F}{F^{*}}, \frac{\mathrm{BD}}{\mathrm{BC}}}=\sqrt{F F^{*}} \\
\operatorname{for}\left(F>F^{*}\right) & \frac{\mathrm{CE}}{\mathrm{AC}}=\sqrt{\frac{(1.0-F)}{\left(1.0-F^{*}\right)}} \\
\frac{\mathrm{CD}}{\mathrm{BC}} & =\sqrt{(1.0-F)\left(1.0-F^{*}\right)}
\end{aligned}
$$

$3 \cdot 4$ 界面輸送法 $3 \cdot 3$ 節で再構築した気液界面 を用いて, 図 4(a)-(g) と式(4)に示すように5 通りの場合 に分け輸送流量 $\Delta F$ を算出する. ここで輸送の際に使 用する要素境界辺で定義した速度には各辺の法線方向 成分を使用した. 初めに計算する境界辺に平行で, 距 離が $\delta t \cdot u_{\text {norm }}$ である直線を仮定し, 境界辺と台形を作 る. この台形は境界辺を通して隣の要素へ流出する流 体の総流量である.このうち, 今注目している流体が 占める量は, 図のように注目している流体と構築した 台形が重なる部分, すなわち図中の斜線部となる.し たがって, 斜線部の面積を幾何学的に計算することに より各要素境界を通過する輸送流量 $\Delta F$ が算出できる.

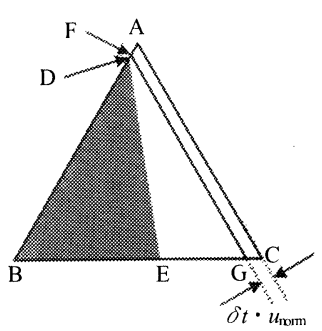

(a)

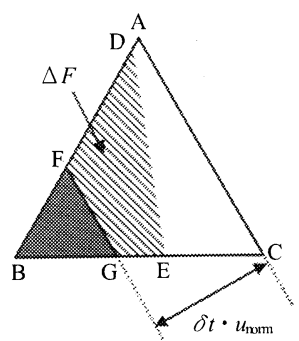

(c)

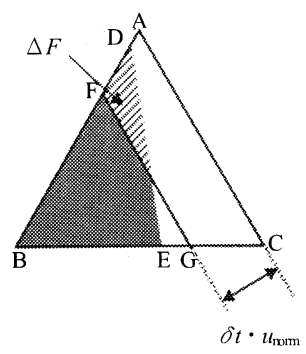

(b)

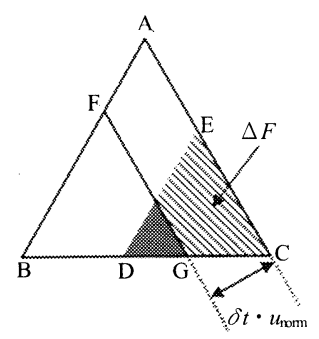

(d)

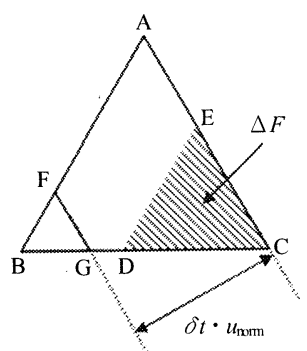

(e)

Fig.4 Advection of fluid volume

$$
\begin{aligned}
& \Delta F= \\
& \text { for }(a) \quad 0.0 \\
& \text { for }(b) \quad F \frac{\left(u_{n}-\mathrm{AD} / \mathrm{AB}\right)^{2}}{(\mathrm{BD} / \mathrm{AB})(\mathrm{CE} / \mathrm{BC}-\mathrm{AD} / \mathrm{AB})} \\
& \text { for }(c) \quad F-\left(1.0-u_{n}\right)^{2} \\
& \text { for }(d) \quad F\left[1.0-\left(\frac{\mathrm{CD} / \mathrm{BC}-u_{n}}{\mathrm{CD} / \mathrm{BC}}\right)^{2}\right] \\
& \text { for }(e) \quad F
\end{aligned}
$$


ここで

$$
u_{n}=\frac{\delta t \cdot u_{n o r m}}{2 V / \mathrm{BC}}
$$

であり，輸送時間あたりに輸送する台形の高さと三角 形の高さの比である. 気相と液相が逆の場合は台形 $\mathrm{AFGC}$ と式(4)で求めた值の差をとることにより $\Delta F$ を 求めることができる.

\section{4. 数値解析}

非構造格子系において, 界面法線ベクトルの計算法 の精度と, 考案した界面輸送法の精度を検証するため, 剛体輸送問題を解析した. 本章ではその結果について 述べる.

4・1 界面法線ベクトルの計算精度 非構造格子 系における ALE形式とMAC形式の界面法線ベクトル 計算法による精度検証を行った. 図 5 に示す市販ソフ トを用いて作成した非構造メッシュ上に円を配置し， 前述した 2 種類の計算スキームで界面法線ベクトルを 計算した. 円の半径は $0.03[\mathrm{~m}]$, メッシュあたりの面積 は $5.01 \times 10^{-7}\left[\mathrm{~m}^{2}\right]$ である.

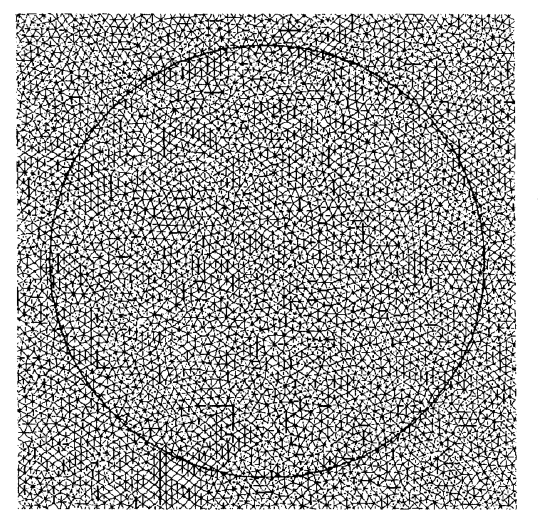

Fig.5 Calculation domain

図 6 は界面法線ベクトルを ALE 形式と MAC 形式 について示したものである. 計算上は界面が存在しな い要素中にも法線ベクトルか現れるが, 本論文では表 面張力の計算は行っておらず, 気液界面の再構築およ び輸送には無関係なため, 界面が存在する要素におけ る法線ベクトルのみを対象に精度の検討を行った. 図 6 より，ALE 形式が MAC 形式に比べ界面を滑らかに 捉えていることが分かる.

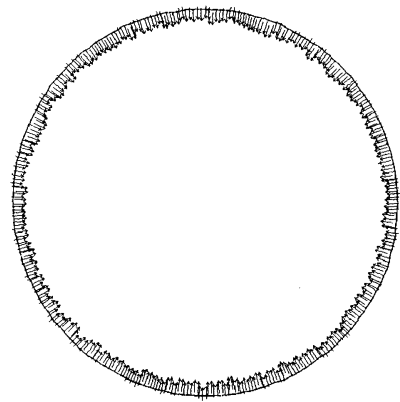

(a)ALE-like

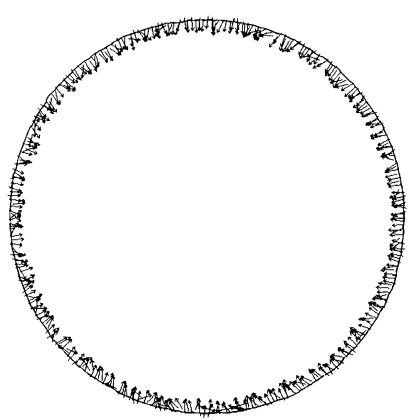

(b)MAC-like

Fig.6 Surface normal vector

この精度を定量的に検討するため誤差評価を行つ た. 具体的には, 界面が存在する要素毎に法線ベクト ルの理論値と計算で求めた法線ベクトルとの内積を求 め, 以下の式で誤差を評価した. ここで, 法線ベクト ルの理論值とは要素中心から配置した円の中心へ向か う単位ベクトルである.

$$
E=\frac{\sum_{\text {surface }}\left(\mathbf{n}_{\text {theo }} \cdot \mathbf{n}_{\text {theo }}\right)-\sum_{\text {surface }}\left(\mathbf{n}_{\text {cal }} \cdot \mathbf{n}_{\text {theo }}\right)}{\sum_{\text {surface }}\left(\mathbf{n}_{\text {theo }} \cdot \mathbf{n}_{\text {theo }}\right)}
$$

ここでは, 界面が存在する要素について総和を取つて いる. また図 5 と同様の体系で，メッシュサイズのみ を変化させた結果を表 1 に示した. casel は図 5 の結果 であり, case2 は要素あたりの面積を $2.81 \times 10^{-7}\left[\mathrm{~m}^{2}\right]$, case3 は $1.30 \times 10^{-6}\left[\mathrm{~m}^{2}\right]$ とそれぞれメッシュを細かく, または粗くしたものである. 今回用いたメッシュ体系 では, ALE形式はメッシュを細かくすると精度が高く なっており, 妥当な結果となっている. MAC 形式の 精度はメッシュのサイズにあまり依存しない結果とな った.このことより，2 種類の形式を比較すると, ALE 形式が MAC 形式に比べ高精度であることが分かる. 
これは積分範囲の広い ALE 形式のスキームの方が高 次の空間補間となっているため, メッシュ形状に対す る依存性が小さいものと考えられる，したがって，本 節以後の解析には ALE 形式用いている.

Table1 Error of surface normal vector

\begin{tabular}{|c||c|c|c|}
\hline & case1 & case2 & case3 \\
\hline \hline Mesh area $\left[\mathrm{m}^{2}\right]$ & $5.01 \times 10^{-7}$ & $2.81 \times 10^{-7}$ & $1.30 \times 10^{-6}$ \\
\hline \hline ALE-like & $6.941 \times 10^{-6}$ & $3.992 \times 10^{-6}$ & $1.765 \times 10^{-5}$ \\
\hline MAC-like & $9.728 \times 10^{-2}$ & $1.015 \times 10^{-1}$ & $1.071 \times 10^{-1}$ \\
\hline
\end{tabular}

\subsection{Zalesak の剛体回転問題 界面輸送法の精} 度を検証するため, この種のベンチマークとして知ら れるZalesak の剛体回転問題(9)を実施した. 図 7 に計算 体系を示す．初期に配置した切り欠きのある円を反時 計回りに 1 回転させ, 回転前と回転後の形状を比較し た. 本解析では, タイムステップが形状・体積保存性 へ与える影響を調ベるためフラクショナルステップ数 を変えた条件で行った. ここでフラクショナルステッ プとは, 1 タイムステップあたり式(1)の連続式を複数 回解くことにより界面再構築の精度を上げる手法であ り, 構造格子系 MARS においても使用されている(5). 今回は 1 タイムステップを 10 分割と 50 分割した場合 について解析を行った. ここで, タイムステップは 1.0 $\times 10^{-3}[\mathrm{~s}]$ ，すなわちフラクショナルステップ数が 10 の 場合は $\delta t=1.0 \times 10^{-4}[\mathrm{~s}], 50$ の場合は $\delta t=2.0 \times 10^{-5}[\mathrm{~s}]$ となる.このタイムステップは構造格子系においても 同じ值に設定した. メッシュは前節の casel と同じも のを利用し，また比較のために，構造格子系における 解析も同様に行った. 構造格子のメッシュサイズは 5.0 $\times 10^{-4}[\mathrm{~m}]$ であり゙，1 メッシュあたりの面積は $2.5 \times$ $10^{-7}\left[\mathrm{~m}^{2}\right]$ で非構造格子のおよそ半分である.

図8は剛体を一回転させた形状を初期形状と比較し たものである. 図 8-(a)の初期形状の切り欠きの直線部 分及びエッジ部分がシャープに配置されていないよう に見えるが，これは可視化の際に值を格子点へと補間 しているためにエッジ部分などが鈍されてしまう可視 化ソフトの問題である. 図 8-(b)と(c)の比較から非構造 格子系におけるフラクショナルステップによる形状の 違いはほとんど見られず，フラクショナルステップ数 が 10 程度でこの手法における形状保存性が十分に保 たれていることが分かる. また図 8-(d)の構造格子系と の比較において, 一方輸送後の切り欠きの部分の形状 などもほぼ同様であることより，形状保存性は構造格 子系とほぼ同等であると言える.
図 9 は回転輸送中の輸送面積の誤差を示したグラフ である.これは以下の式で面積の誤差 $\varepsilon(\Delta F)$ を評価し たもので, 縦軸を䛊差, 横軸を時間としてプロットし たものである.

$$
\varepsilon(\Delta F)=\frac{\sum_{e}\left(F_{e}^{t} V_{e}\right)-\sum_{e} F_{e}^{t_{0}} V_{e}}{\sum_{e} F_{e}^{t_{0}} V_{e}}
$$

非構造格子系における輸送面積の誤差は最大で, フ ラクショナルステップ 10 分割が $4.0 \times 10^{-5}, 50$ 分割が $7.0 \times 10^{-6}$ 程度となっており, 構造格子系の值 $5.0 \times 10^{-6}$ と比較して 50 分割したものは界面追跡手法としては 十分な精度を有していると言えよう。

しかし， 10 分割の場合には 0. 3 秒付近に最も誤差 が大きくなる部分や，全体として周期性が見られる.

これはメッシュサイズが面積保存性に影響を与えてい ると考えられる.このメッシュサイズの影響に関して は次節で議論を行う。しかし，フラクショナルステッ プを適切に用いることにより, 構造格子系と同等の面 積保存性を有する界面輸送解析が可能であることが分 かった.

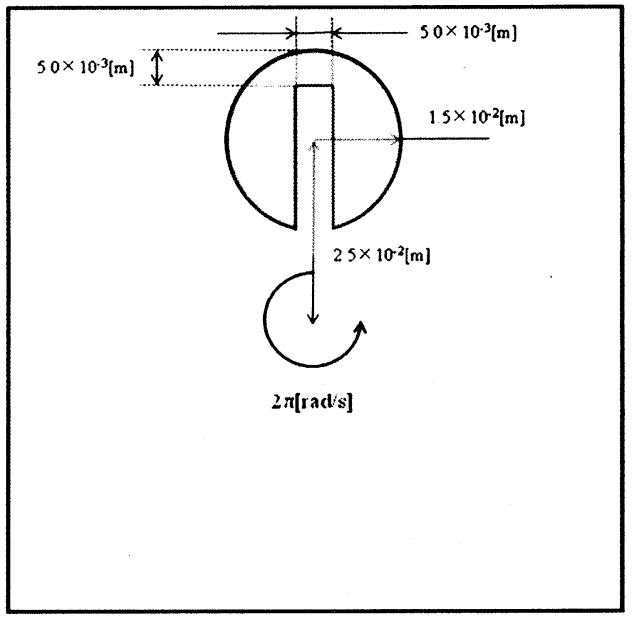

Fig.7 Rotated disk problem 


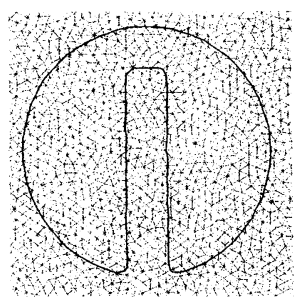

(a) Original

(unstructured grid)

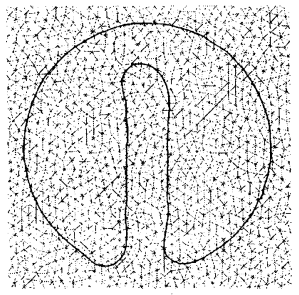

(c) Fractional steps:50 (unstructured grid)

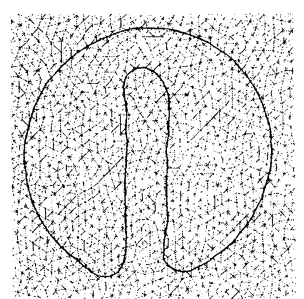

(b) Fractional steps :10 (unstructured grid)

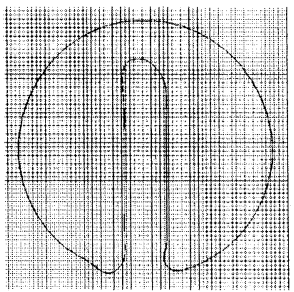

(d) Fractional steps: 10 (structured grid)
Fig.8 Shape of rotated disk

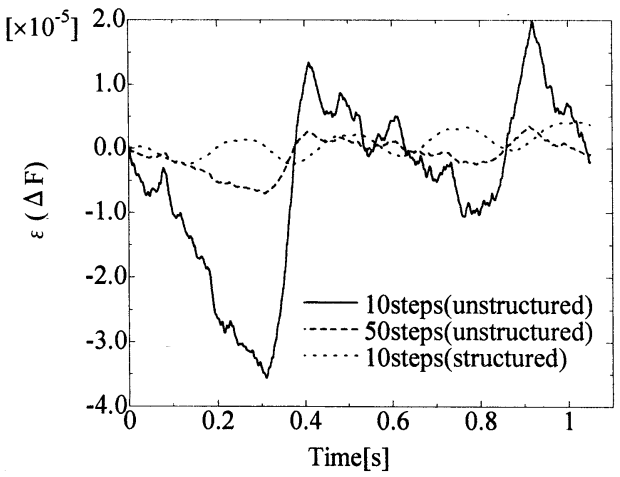

Fig.9 Error of volume conservation

$4 \cdot 3$ 異なるメッシュサイズ領域内を移動する場合 の剛体輸送 図 10 に示すメッシュを用いて, 正方 形の剛体を $1.0 \times 10^{-1}[\mathrm{~m} / \mathrm{s}]$ の速度で右方向へ輸送した. このメッシュは図に示すように左側から右側へ向かっ て2つの部分でメッシュが粗くなっている.メッシュ あたりの面積は細かい方から順に $2.632 \times 10^{-8}\left[\mathrm{~m}^{2}\right]$, $1.096 \times 10^{-7}\left[\mathrm{~m}^{2}\right], 4.211 \times 10^{-7}\left[\mathrm{~m}^{2}\right]$ となっており, 面積でお よそ4倍になっている. これにより，メッシュサイズ が形状・面積保存性に与える影響を調べることができ る. 図 11 は初期状態からの形状の変化を示しており, 配置してある正方形は一辺 $2.0 \times 10^{-2}[\mathrm{~m}]$, 計算領域の高 さは $3.0 \times 10^{-2}[\mathrm{~m}]$, タイムステップは $1.0 \times 10^{-3}[\mathrm{~s}]$, フ ラクショナルステップは 10 分割として, 右側へ輸送し
た. 図中の形状は左側から順番に $0.0[\mathrm{~s}], 3.0 \times 10^{-1}[\mathrm{~s}]$, $7.0 \times 10^{-1}[\mathrm{~s}]$ 経過後の様子であり，メッシュサイズが異 なる領域内に剛体が輸送された際のスナップショット である.メッシュが粗くなるに従い角の部分が鈍され ており，形状を保存するには解析条件に応じてメッシ ユサイズを局所的に変更する必要のあることが分かる。

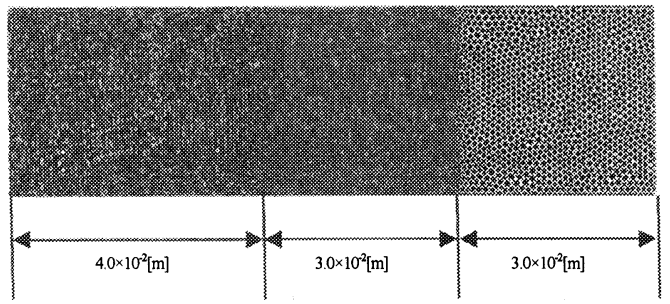

Fig.10 Computational domain

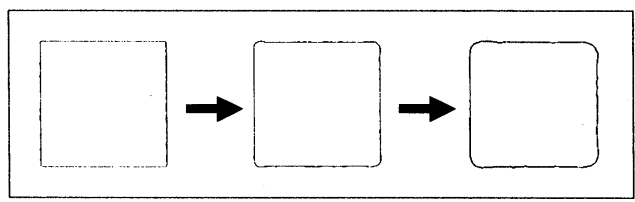

Fig.11 Shape of square in different mesh size

次に異なるサイズのメッシュによる面積保存性を 検討するため，図 9 と同様に縦軸に式(7)で計算される 輸送面積の誤差を，横軸に時間をプロットしたグラフ を図 12 に示す. $4 \cdot 2$ 節の輸送面積の誤差と比較する と $3.0 \times 10^{-3}$ 程度とかなり精度が低下している. またグ ラフの形状は， $0.15[\mathrm{~s}]$ から $0.35[\mathrm{~s}]$ と $0.45[\mathrm{~s}]$ から $0.65[\mathrm{~s}]$ へかけて大きく低下していることが分かる．これらの 時刻はちょうど輸送する剛体がメッシュサイズの異な る部分を通過する時刻と一致しており，メッシュサイ ズの異なる部分を通過する際に面積保存性が損なわれ ていることが分かる.この面積保存性の低下の原因に ついて考察する.

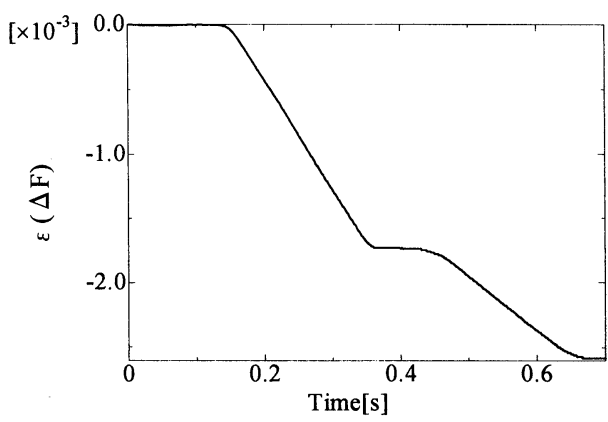

Fig.12 Error of volume conservation 
図 13 にメッシュサイズが異なる部分の模式図を示 す. 図中の矢印は各境界辺に垂直な速度成分であり, この速度で VOF 率の輸送を行っている. 本解析手法 では, 辺中心に定義された輸送速度として輸送方向の 速度ベクトルを各辺の法線ベクトル方向へ射影した速 度を用いており, この速度場はソレノイダル条件を満 たしていない、ソレノイダル条件を満たす速度場であ れば式(1)の $F \nabla \cdot \mathbf{u}$ の項が 0 となるため, 厳密に面積 保存性を保った輸送ができるが，一般に数值解析では この項は厳密には 0 とはならず, この項は輸送量の面 積保存誤差を修正する項として作用する. 本解析にお いて, 図 13 の色付きの要素の例では, 輸送量は流出量 が流入量より大きくなるため, $F \nabla \cdot \mathbf{u}$ が発生し,この 面積輸送量の修正により全体として VOF 率の増加や 減少を引き起こすこととなる.このことは 4 ・ 2 節の解 析でも見られ，そこで述べた面積保存性が損われた時 間がフラクショナルステップ数に依らないのは, メッ シュサイズが異なる部分を通過しているためであると 考えられる. また, 周期性については, 逆にメッシュ が小さくなる場合今までの議論の逆のこと, すなわち 大きくなる場合は VOF 率アンダーシュートが, 小さ くなる場合はオーバーシュートが起こり, 補正が各々 の場合逆に働くこととなる.このため, 剛体が 1 回転 して元の位置に戻ることにより, 補正による収支が釣 り合い，面積保存誤差がほぼ 0 となるためである.し かし, これら保存性の低下は, 圧力ポアソン方程式を 解き, 速度場がソレノイダル条件を満たせば改善する 本手法に特有の問題であると考えられる.

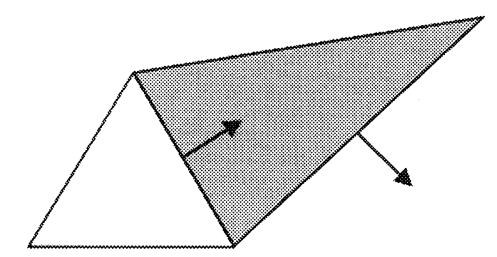

Fig.13 Conservation failure of unstructured mesh system

\section{5. 結論}

MARS に基づく非構造格子系における界面輸送法 を考案し, 形状と面積の保存性について検証すること により, 本手法の有用性を示す以下の結論を得た.

(1) CSF モデルの界面法線ベクトル計算を ALE 形式と MAC 形式スキームの 2 種類で実施し, 算出された 法線ベクトルの誤差を評価した. その結果, 要素頂
点で界面法線ベクトルの計算には, 高精度の ALE 形式スキームを用いるべきであることが示された.

(2) Zalezak の剛体回転問題を実施し，その形状・面積 保存性を構造格子系 MARS との比較により検証し た.これにより, 本輸送法はフラクショナルステッ プ数を適切に選ぶことにより,構造格子系と同程度 の形状・面積保存性を満たすことを確認した.

(3) メッシュサイズが異なる領域における界面輸送の 場合の形状・面積保存性に与える影響について検討 した. その結果, メッシュサイズが大きく変化する ことで, 解像度が低下して形状に鈍りが生じ, また メッシュサイズの異なる領域を通過する際に面積 保存性が損なわれるという結果を得た. 前者は構造 格子系でも同様であり,解析に十分な解像度を有す るメッシュを使用することにより解決でき, 後者は 圧力ポアソン方程式を解いて速度場がソレノイダ ル条件を満足する状態で界面輸送を行うことで解 決できると考える.

以上より, 本研究で考案した非構造格子系 MARS は界面面積（3 次元では体積）追跡法として有望であ ると言える.

\section{文献}

(1) Harlow, F. H., Welch, J. E., Numerical Calculation of Time-Dependent Viscous Incompressible Flows of Fluid with Free Surface, Physics of Fluids,Vol.8(1965), pp.2182-2189.

(2) Hirt, C., Nichols, B.D., Volume of Fluid Method for the Dynamics of Free Boundaries, Journal of Computational Physics, Vol.39(1981), pp.201-225.

(3) Sussman, M., Smereka, P., Osher, S., A Level Set Approach or Computing Solutions to Incompressible Two-Phase Flow, Journal of Computational Physics, Vol.114(1994), pp.146-159.

(4) Yabe. T., Xiao, F., Utsumi, T., The Constrained Interpolation Profile Method for Multiphase Analysis, Journal of Computational Physics, Vol.169(2001), pp.556-593.

(5) Kunugi, T., MARS for Multiphase Calculation, Computational Fluid Dynamics Journal, Vol.9(2001), pp.563-571.

(6) Brackbill, J. U., Kothe., D. B., Zemach, C., Continuum Method for Modeling Surface Tension, Journal of Computational Physics, Vol.100 (1992), pp. 335-354.

(7) Blazek, J., Computational Fluid Dynamics: Principles and Applications, Elsevier (2001)

(8) Yang, X.. James, A. J., Analytic Relations for Reconstructing Piecewise Linear Interfaces in Triangular and Tetrahedral Grids, Journal of Computational Physics, Vol. 214(2006), pp.41-54.

(9) Zalesak, S. T., Fully Multidimensional Flux -Corrected Transport Algorithms for Fluids, Journal of Computational Physics, Vol.31(1979), pp.335-362. 